\title{
Observatorio de prácticas de desarrollo de software en MinPyme y pymes de Bogotá*
}

\author{
Observatory of software development practi- \\ ces in Bogota Pymes and MinPymes \\ Observatório de práticas desenvolvimento de soft- \\ ware em Bogotá mpmes e as pme
}

Recibido: febrero de 2012 Aprobado: junio de 2012
Alexandra Abuchar Porras ${ }^{2 * *}$ Beitmantt Cárdenas Quintero ${ }^{3 * * *}$ Danilo Alfonso López $z^{4 * * *}$

\section{Resumen}

El objetivo principal de este artículo es detectar las prácticas de desarrollo de software en las pequeñas y medianas empresas de Bogotá que se dedican a esta labor. En la primera parte de la investigación, se hace una aproximación a los conceptos de empresa, cadenas productivas y clúster de software. Posteriormente, se aplica una encuesta a 100 empresas del sector, con el fin de evidenciar que el $45 \%$ de estas ubica a sus clientes en el sector de la industria y servicios, el $24 \%$ en la banca y seguros, el $15 \%$ en las telecomunicaciones y el 16\% en la administración pública. En cuanto al levantamiento de requerimientos: el $40 \%$ aplica entrevistas, el $22 \%$ cuestionarios y encuestas, el $14 \%$ casos de uso, el $7 \%$ realiza prototipos, el $5 \%$ organiza reuniones JAD, y solo el $2 \%$ practica la lluvia de ideas. Sumado a lo anterior, los proyectos de software (que comprenden un 53\%) están dentro del rango de proyectos cortos, con entregas exitosas pero sobre las que se detecta una demora en la entrega final.

Palabras clave: software, metodologías, prácticas software, clúster software

\section{Abstract}

In this articule you will find the results of the investigative Project entitled: observatorio de las prácticas de desarrollo de software en las pequeñas y medianas empresas de desarrollo de software en la ciudad de Bogotá, approved by the investigation center of the distrit university Francisco Jose de Caldas, made in 2010 and 2011, with the objective of detect development practices

* Este artículo presenta los resultados del proyecto de investigación "Observatorio las prácticas de desarrollo de software en las pequeñas y medianas empresas de desarrollo de software en la ciudad de Bogotá", aprobado por el Centro de Investigaciones de la Universidad Distrital Francisco José de Caldas y realizado durante el 2010 y 2011.

** Magister Informática Aplicada a la Educación de la Universidad Cooperativa de Colombia; Ingeniera de Sistemas de la Universidad Antonio Nariño; Especialista en Multimedia para la Docencia de la Universidad Cooperativa de Colombia y Especialista en Docencia Universitaria de la misma universidad; Docente de la Universidad Distrital Francisco José de Caldas. Correo electrónico: aabucharp@udistrital.edu.co, alexandraabucharyahoo.com.mx

*** Ingeniero de Sistemas de la Universidad de Boyacá; Especialista en Ingeniería de Software de la Universidad Antonio Nariño; Magíster en Ciencias de la Información y las Telecomunicaciones de la Universidad Distrital Francisco José De Caldas. Correo electrónico: beitmantt@yahoo.com

***** Magíster en Teleinformática e Ingeniero Electrónico de la Universidad de Pamplona. Correo electrónico dalopezs@udistrital.edu.co 
of observatorio de las prácticas de desarrollo de software en las pequeñas y medianas empresas de desarrollo de software en la ciudad de Bogotá.

The topic investigation was about the approximation to the company concept, the production chains, and the software cluster. A survey was made to 100 companies: the $45 \%$ answer to their customers with services and industry, the $24 \%$ in the bank and secures area, the $15 \%$ with television communications and the $16 \%$ in public administration. In the side of requirements, the $40 \%$ do it with interviews, $22 \%$ with surveys and questionnaires, the $14 \%$ do it with use case, and the $7 \%$ create prototypes, the $5 \%$ organize JAD meetings and the $12 \%$ practice brain storm.

Also, that software projects are inside the range of the short projects, with the $53 \%$ of success deliveries considering the general observation of the long time to give the final work.

Key words: software, methodology, practices software, cluster software

Neste artigo, você vai encontrar os resultados do projeto de pesquisa, intitulado práticas observatório de desenvolvimento de software em empresas de software de pequeno e médio desenvolvimento na cidade de Bogotá, projeto aprovado pelo centro de pesquisa da Universidade Francisco José de Caldas. Feito em 2010 e 2011, como seu principal objetivo é detectar as práticas de desenvolvimento de software em empresas de desenvolvimento de pequenas e médias empresas de software na cidade de Bogotá,

\section{Resumo}

Ao abordar a questão é uma abordagem a conceitos de negócios, cadeias de produção e software de cluster. Uma pesquisa com 100 empresas em evidência: a de que $45 \%$ responderam que seus clientes são na área da indústria e serviços, $24 \%$ no setor bancário e de seguros, telecomunicações, 15\% e 16\% em administração pública. Quanto aos requisitos de entrevistas de elicitação aplicar $40 \%, 22 \%$ de questionários e pesquisas, casos de uso de $14 \%, 7 \%$ protótipos feitos, $5 \%$ reuniões JAD organizado e praticado sozinho e L 2 chuva\% idéias.

Para além dos projectos de software estão dentro da gama de projectos curtos com entregas $53 \%$ e bem sucedida, mas com a observação generalizada em retardar a entrega final.

Palavras-chave: software, metodologias, práticas de software, software de cluster

\section{Introducción}

Una ciudad como Bogotá ofrece políticas favorables para los productos de software en las diferentes actividades empresariales. Por ejemplo, dichas actividades son fundamentales para orientar las decisiones de los entes educativos a nivel superior, a las empresas y profesionales en las áreas afines, así como para identificar las prioridades y las políticas que se deben adoptar a la hora de elevar el crecimiento, el empleo y la calidad de vida. Esta situación llevó a plantear la pregunta central de esta investigación: ¿cómo se están llevando a cabo las prácticas de desarrollo de software en las pequeñas y medianas empresas de desarrollo de software en Bogotá? Para responder esta interrogante se recolectó información sobre las cadenas productivas y clúster, en donde se desenvuelven las 
pequeñas y medianas empresas de Bogotá, dedicadas al desarrollo de software. Además de lo anterior, se identificó, según la cadena de producción del software, los cuatro componentes.

La investigación se desarrolló en el año 2011 y se justificó gracias a que después de la obtención de los datos y su posterior análisis, se podría aportar valiosa información acerca del sector de desarrollo del software. Siendo posible, además, iniciar una línea temática para la identificación de deficienciafortalezas de los procesos de desarrollo del software y de los errores más comunes de las empresas clúster de software. Así, ubicando los puntos débiles, se generaron distintas estrategias a nivel empresarial pero también académico, pues desde el propio currículo se podían fortalecer las falencias que se manifestaban luego en el mundo laboral. Lo cual permitió generar una actuación tanto a corto como a mediano y largo plazo.

\section{Una aproximación al clúster del software}

Según Chevalier y Toledo (1978), "La cadena es un conjunto articulado de actividades económicas integradas; integración consecuencia de articulaciones en términos de mercado, tecnología y capital". A lo anterior se suma la postura de Malassis (1992), según la cual el producto está íntimamente unido al uso; además, la cadena productiva que le da esa identificación permite, a su vez, localizar el tipo de empresas. Conviene resaltar que dentro de una cadena productiva existe un término de necesaria referencia: clúster. Este alude a un conjunto de empresas que establecen vínculos de interrelación a nivel funcional, bien sea para el desarrollo de los diferentes procesos o la obtención de productos específicos de una cadena productiva. Dicho de otro modo, un clúster podría ser un agregado de empresas de diversos sectores que, localizadas en una zona territorial limitada, están interrelacionadas en torno a los mercados, las tecnologías y los capitales productivos; formando así un sistema interactivo en el que -gracias al apoyo administrativo- logran la competitividad esperada.

Dentro de las cadenas productivas, la de servicios es la de mayor demanda y, debido a que es utilizada por las demás, en esta está el clúster de software. La siguiente gráfica muestra el porcentaje en ésta cadena frente a las demás, según estudios realizados por la Secretaría de Hacienda Distrital.

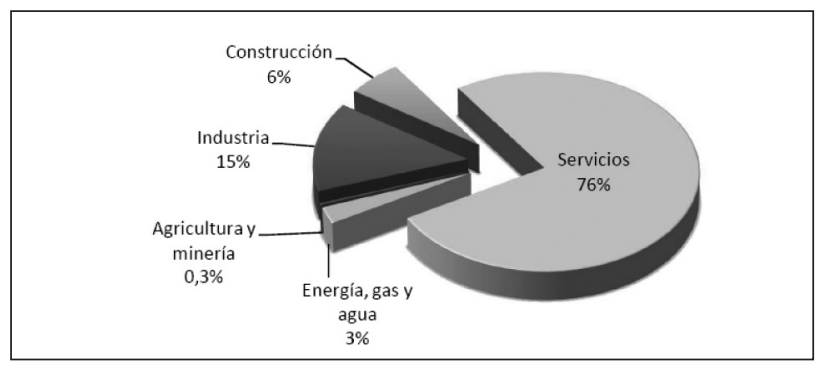

Gráfica 1. Distribución productiva Bogotá

Fuente: Secretaría de Hacienda Distrital. Cifras a 2008

\section{Generalidades de la cadena productiva industria de software}

La industria del software está estrechamente relacionada con la globalización, ya que proporciona, a las empresas dedicadas a la elaboración de herramientas de innovación, un control logístico, de versatilidad a nivel productivo y de comunicación efectiva y eficaz. En suma, está estructurada de tal manera que las necesidades informáticas de una empresa, que puede estar en el mismo sector geográfico o distante, puedan ser suplidas oportunamente.

En Colombia la industria de software tiene el potencial de convertirse en un sector económico de gran impacto, que pueda incluso suplir la demanda interna y llegar con éxito a los mercados del exterior. También, por ser este un sector que involucra el manejo transversal a nivel empresarial, puede apoyar y brindar soporte, agilizando los procesos, facilitando la comunicación y reduciendo los costes de operación.

Así mismo, en la industria del software las pyme cuentan con incentivos fiscales para el desarrollo de sus actividades. Así, por ejemplo, los proyectos aprobados por Colciencias y sus intermediarios financieros pueden acceder al Incentivo a la innovación tecnológica; a la exención de IVA para las importaciones de equipos y elementos para la investigación y la innovación tecnológica; y a la 
exención de renta para nuevo software, establecida por la Ley 788 de 2002 para los productos de software desarrollados en Colombia que posean un alto componente de investigación científica y tecnológica nacional. Estudios efectuados por la Cámara de Comercio de Bogotá, referentes al establecimiento de las empresas de desarrollo de software en Cundinamarca, muestran que en Bogotá se encuentra el 97,6\%, mientras que el 2,4\% restante se halla en Soacha, Fusagasugá, Chía y Zipaquirá (ver gráfica 2).

Estas empresas han sido bien calificadas a nivel nacional e internacional. En virtud de lo cual la Cámara de Comercio de Bogotá (2011) realizó la descripción ideal, estableciendo cuatro componentes fundamentales (figura 1, 2 y 3 ):

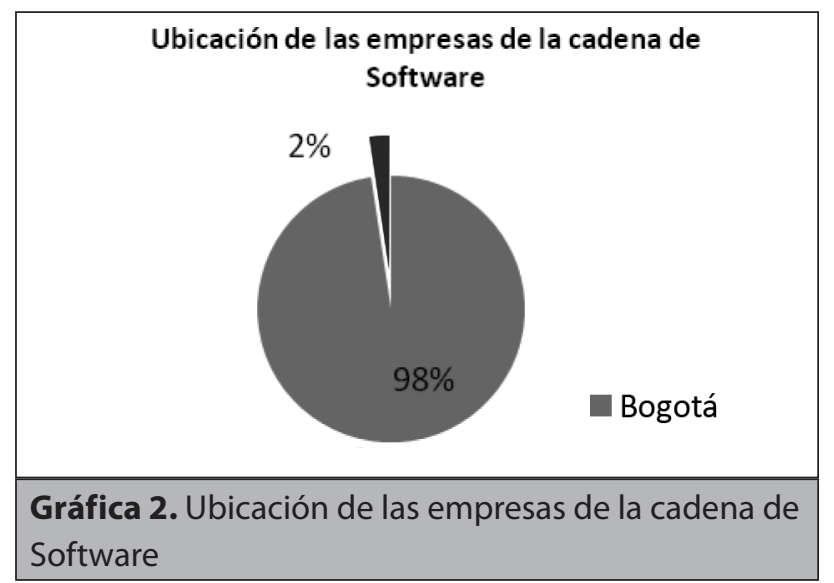

Fuente: elaboración propia

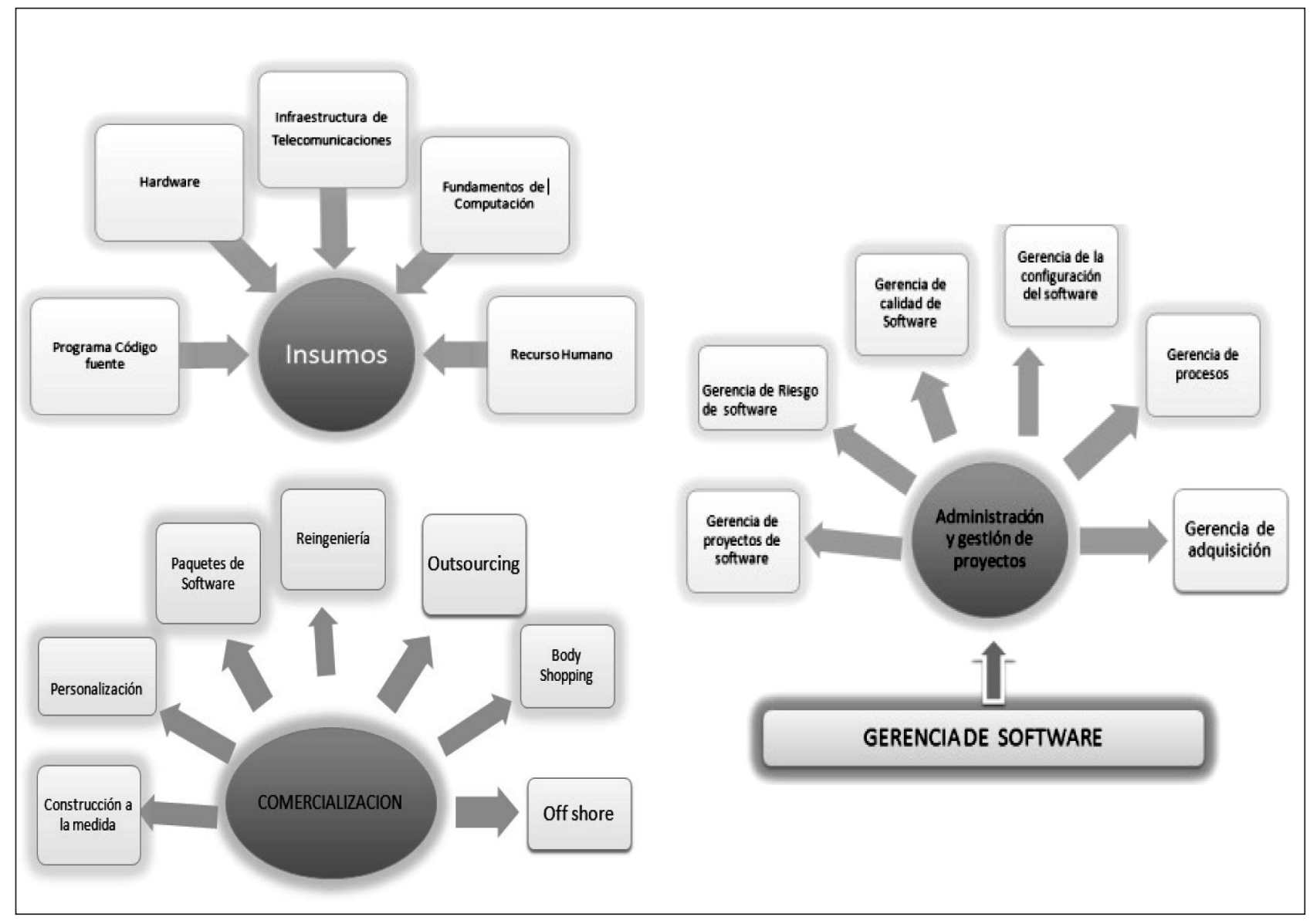

Figura 1. Componentes de la cadena productiva de desarrollo de software

Fuente: elaboración propia 


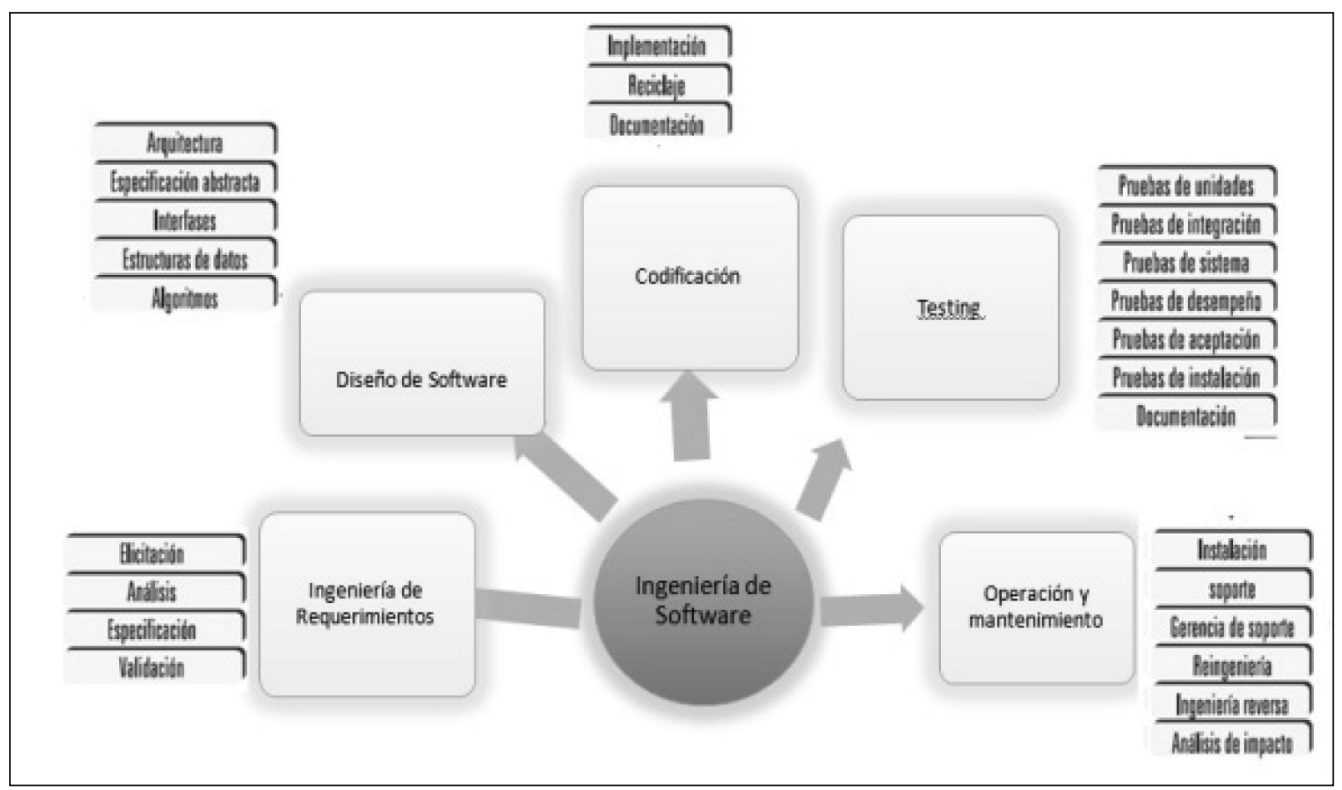

Figura 2. Aproximación de las prácticas de desarrollo de software

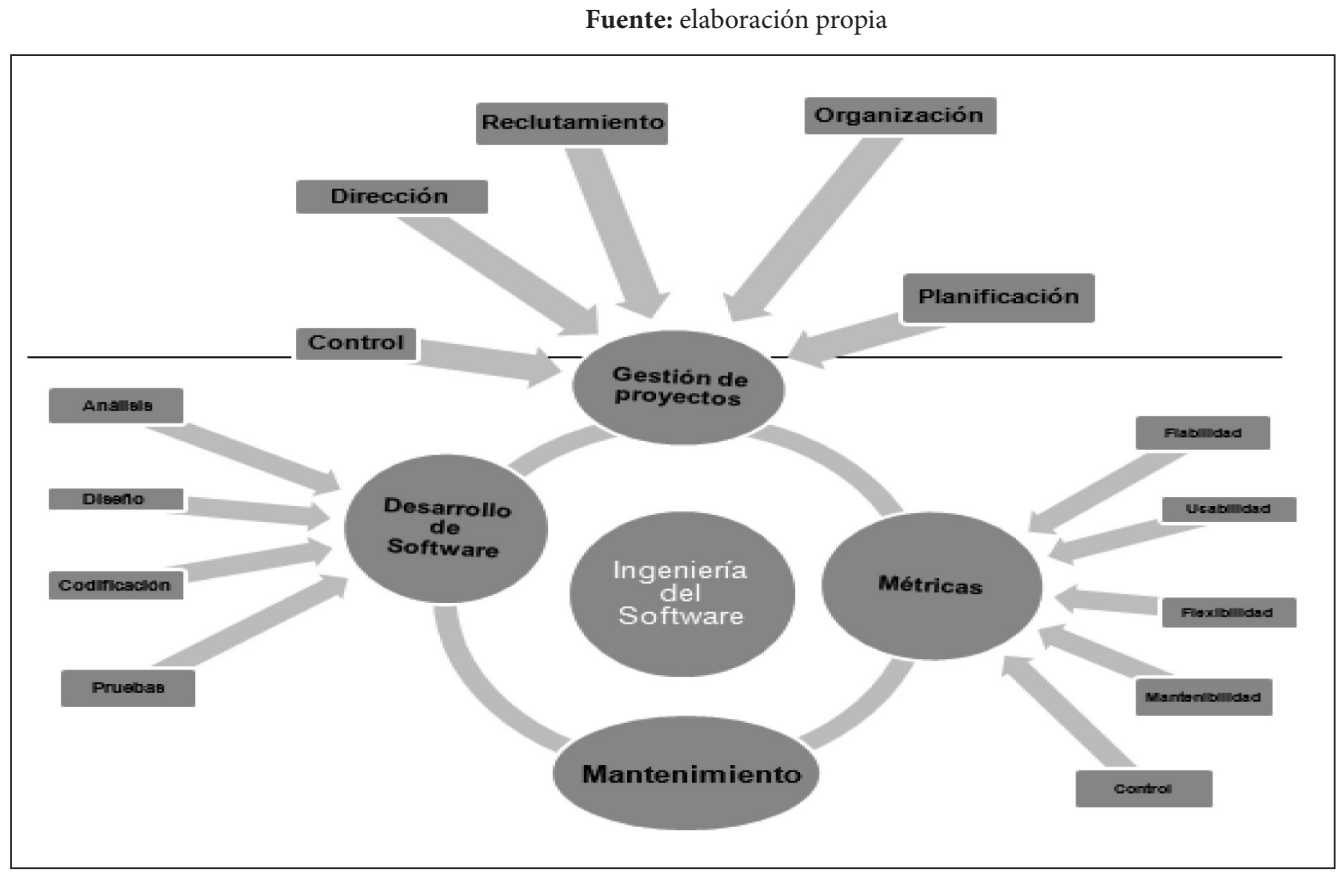

Figura 3. Componente comercialización

Fuente: elaboración propia

Como se mencionó anteriormente, este componente es el eje principal de esta investigación, ya que aquí es donde se realiza el proceso de software y se llevan a cabo las prácticas de desarrollo, de allí que sea importante sondear alguna de ellas. A continuación exponemos las prácticas o aspectos a tener en cuenta para el desarrollo.

\section{Ciclo clásico de vida de un modelo de proceso de desarrollo de software}

Una aproximación lógica de la adquisición, el suministro, el desarrollo, la explotación y el mantenimiento del software. 


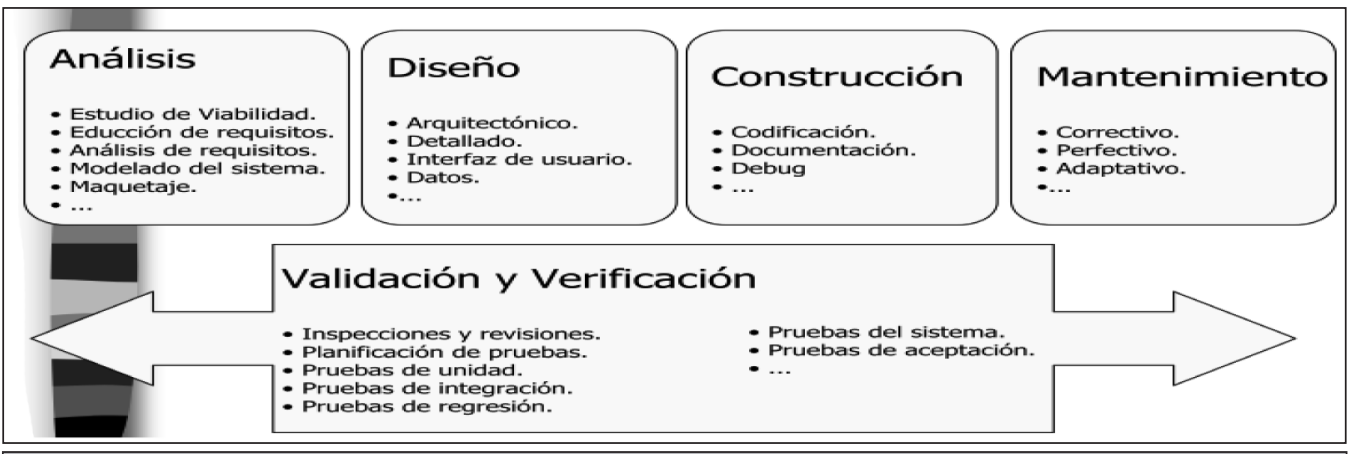

Figura 4. Ciclo clásico del software

Fuente: elaboración propia

\section{Ciclo del desarrollo de software (Pressman 2003)}

- Análisis. En esta etapa es de vital importancia entender y comprender, de forma detallada, cual es el problema a resolver, verificando el entorno o contexto donde se encuentra el mismo, de tal manera que se obtenga la información necesaria para afrontar su respectiva solución. En esta etapa se define el qué de lo que se va a solucionar.

- Diseño. "Una vez que se tiene la suficiente información del problema a solucionar, es importante determinar la estrategia que se va a utilizar para resolver el problema. Esta etapa alude al cómo se va a solucionar.

- Implementación. Partiendo del análisis y diseño de la solución, en esta etapa se procede a desarrollar el correspondiente programa que solucione el problema, mediante el uso de una herramienta computacional determinada.

- Pruebas. Son diversos los errores humanos, cometidos dentro de la programación de los computadores, incluso estos aumentan considerablemente con la complejidad del problema.

- Mantenimiento. Una vez instalado un programa y puesto en marcha para realizar la solución de un problema previamente establecido, es importante mantener una estructura de actualización, verificación y validación que permita a dicho programa ser útil y mantenerse actualizado, según las necesidades o requerimientos planteados durante su vida útil. Para realizar un adecuado mantenimiento, es necesario contar con una buena documentación del mismo"

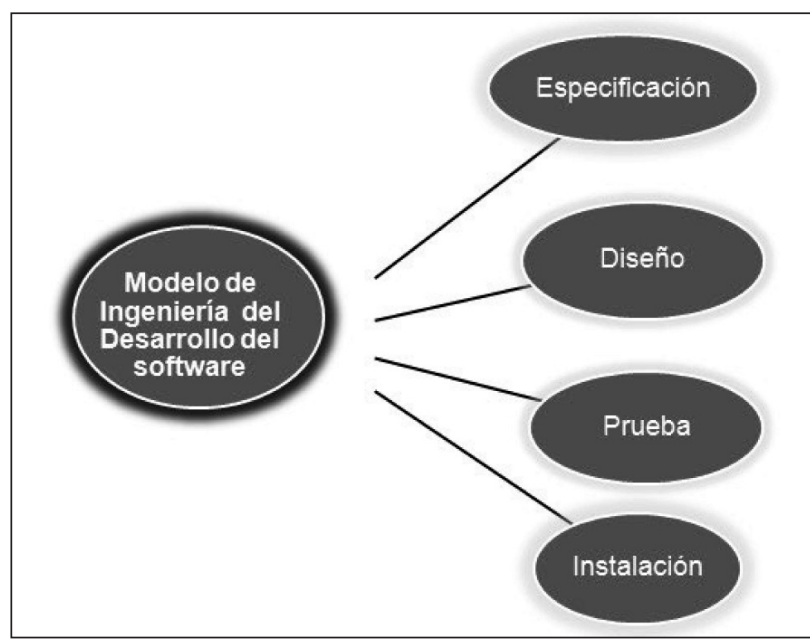

Figura 5. Modelo de ingeniería de software

Fuente: elaboración propia

\section{Modelos de desarrollo de software}

Un modelo de ciclo de vida del software, según la definición dada por los estándares que manejan estos conceptos, es "una aproximación lógica a la adquisición, el suministro, el desarrollo, la explotación y el mantenimiento del software" (IEEE 1074). "Un marco de referencia que contiene los procesos, las actividades y las tareas involucradas en el desarrollo, la explotación y el mantenimiento de un producto de software, abarcando la vida del sistema desde la definición de los requisitos hasta la finalización de su uso" (ISO 122071). Por consiguiente, es una colección descriptiva o prescriptiva de las diferentes actividades que se 
deben incorporar para desarrollar un producto de calidad, a esta colección de actividades se le conoce como cadenas de tareas. Por lo tanto, el modelo representa una continuación de instantes y, al mismo tiempo, una continuación entre ellas. Por ende, existen diferentes modelos de proceso de desarrollo de software. La elaboración de un modelo está compuesta por actividades que tienen un principio, un proceso y un final.

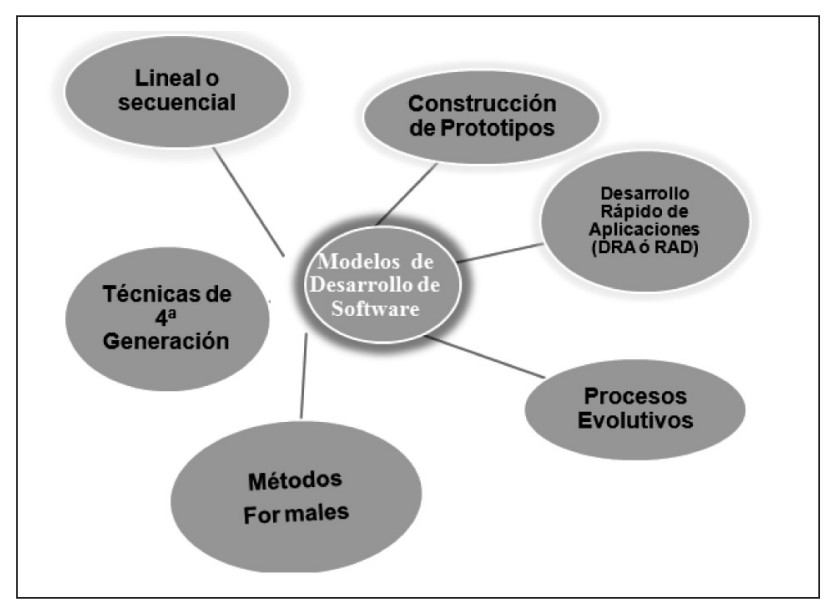

Figura 6. Algunos modelos de desarrollo de software

Fuente: elaboración propia

\section{Estándares o principios de calidad del software}

El presente apartado pretende plasmar, dentro de sus posibilidades, el estado de los estándares más significativos. Primero se establecerá la conceptualización de términos necesarios, por ejemplo, el estándar. Un estándar es un conjunto de criterios documentados para especificar y determinar la adecuación de una acción u objeto. Es importante destacar que los estándares pueden ser desarrollados por la propia compañía, por sociedades profesionales o por organismos internacionales que presentan un cuerpo de conocimientos y un conjunto de principios fundamentales.

La calidad de un sistema software depende de la calidad del proceso usado para su desarrollado. En el software los estándares, por lo general, tienen que ver con el proceso y rara vez con el producto. A continuación se presentan algunas fases de desarrollo del software y el estándar inmerso ellas. Cada una presenta una guía que se debe llevar a cabo.

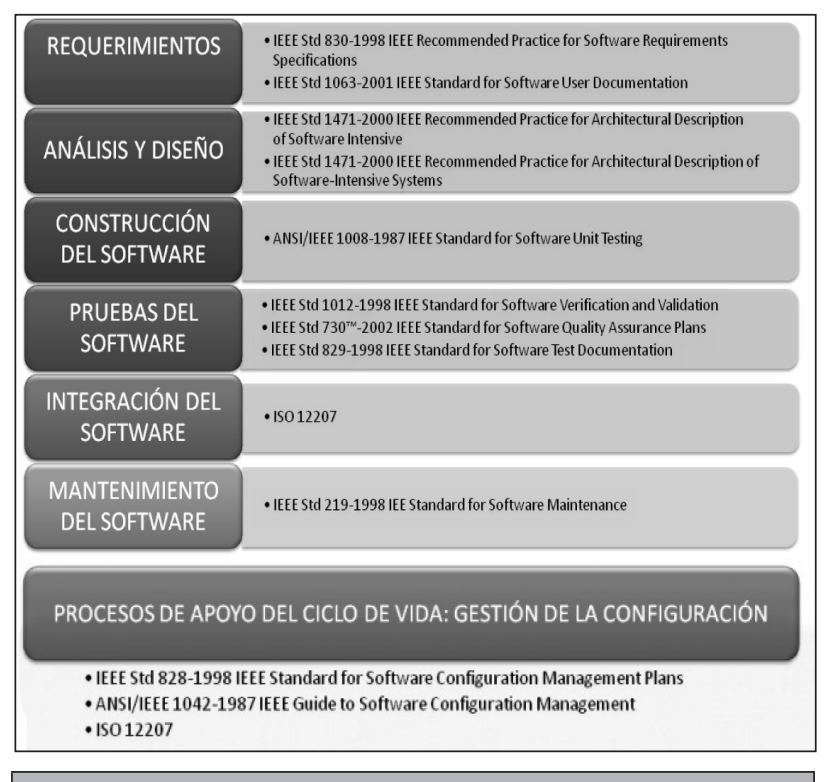

Figura 7.

Fuente: 24 mayo, 2010 - Rodolfo Pérez Kuzma NTP ISO/iec 12119:2005

Por otro lado, es muy importante estar al día con el fortalecimiento de la calidad en el desarrollo del software. Así, por ejemplo, en 2001 se publicó la Guía del cuerpo de conocimiento de ingeniería de software (Guide to the Software Engineering Body of Knowledge o SWEBOK, por sus siglas en inglés), un cuerpo de conocimiento de la ingeniería de software que se divide en áreas de conocimiento (Knowledge) y que comprende los elementos descritos a continuación:

\section{Metodologías de desarrollo de software}

Desde hace algunos años se dice que en el desarrollo de software no hay balas de plata. Y esta afirmación es totalmente cierta, pues no existen las balas de plata, ya que cada proyecto presenta sus propias condiciones y estas lo hacen único. Decir que un modelo, una técnica, una metodología tiene la última palabras es imposible, ya que cada una presenta sus ventajas para desarrollar un buen proyecto de software; sin embargo, sí se debe saber 
escoger la metodología para poder tener un marco metodológico de trabajo específico.

Por ende es necesario establecer que las metodologías de desarrollo de software son un conjunto de filosofías, etapas, procedimientos, reglas, técnicas, herramientas de documentación y aspectos de formación para quien desarrolla el proyecto; es la caja que contiene todo el contenido necesario para que todo esté en su lugar. La metodología contempla todo el proceso del proyecto, no solo el desarrollo del software, sino su contexto y gestión. Escoger la metodología adecuada nos permite saber cómo proceder. Para escoger una metodología de desarrollo de software es importante conocer:

- Las reglas predefinidas del negocio

- El modelo del ciclo de vida

- Saber qué se va a desarrollar en cada etapa

- Tener una planificación y control

- Presentar una comunicación efectiva y eficaz entre los involucrados en el proyecto

- Conocer las herramientas de soporte

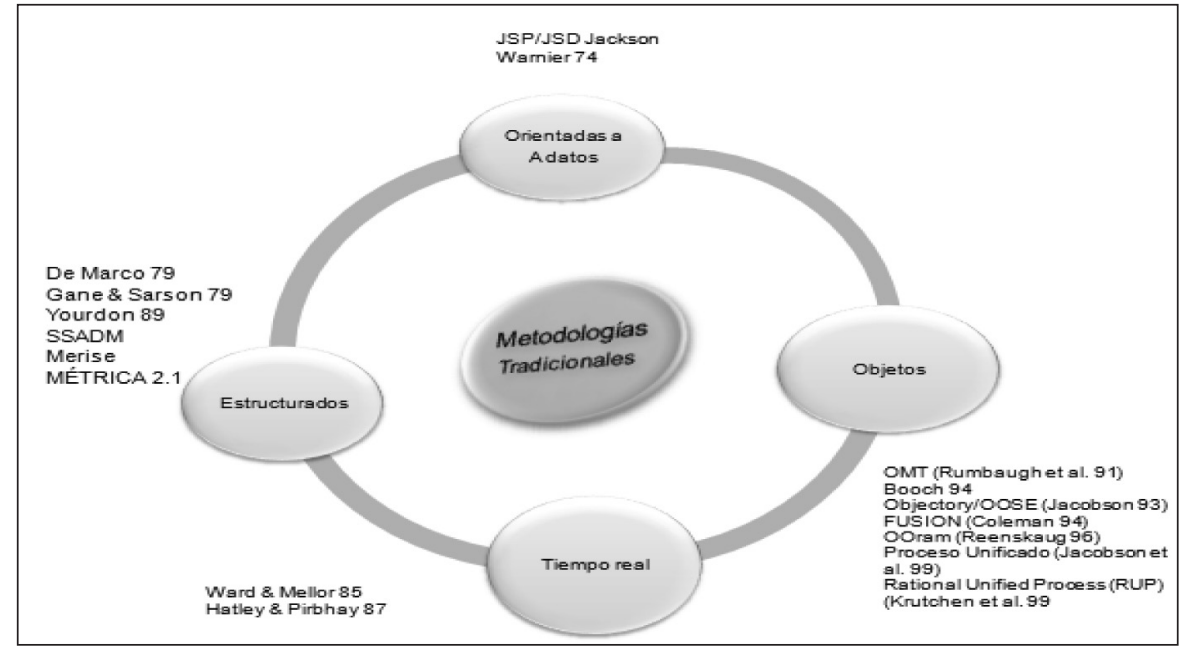

Figura 8.

\section{Metodologías agiles}

Se reunieron 17 expertos de la industria del software: Kent Beck, Arie van Bennekum, Alistair, Cockburn, Ward Cunningham, Martin Fowler James Grenning, Jim Highsmith, Andrew Hunt, Ron Jeffries, Jon Kern, Brian Marick Robert C. Martin, Steve Mellor, Ken Schwaber, Jeff Sutherland Dave Thomas; para analizar qué estaba pasando en la industria con los procesos de software. Luego desarrollaron los valores y principios de una respuesta actual y rápida a los cambios dentro de los proyectos de software, de donde surge el concepto de ágil.

En esta reunión, además del surgimiento del concepto antes mencionado, se creó The Agile Alliance, la cual es una organización, sin ánimo de lucro, dedicada a impulsar y socializar los conceptos relacionados con el desarrollo ágil de software

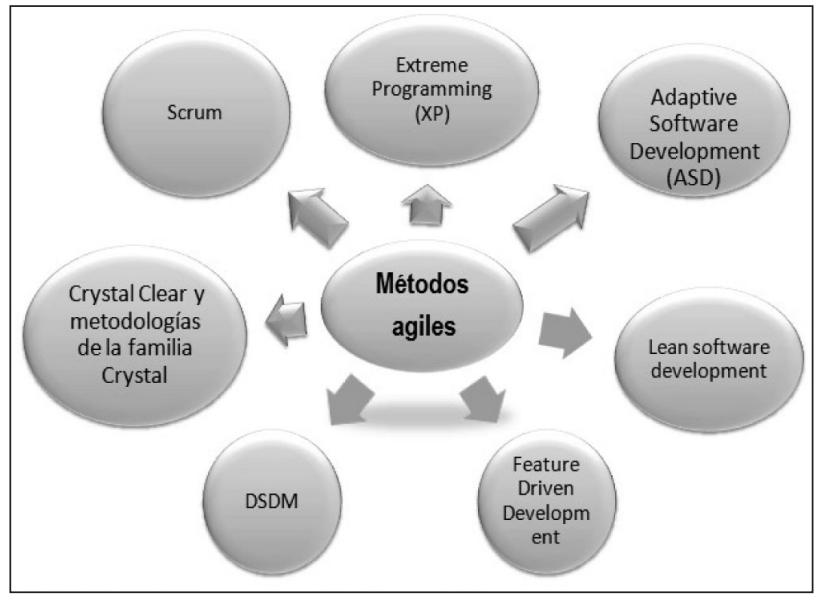

Figura 9. 
y colaborar con las organizaciones que quieran incursionar en esta tendencia. El punto de partida fue el Manifiesto Ágil, un documento que resume la filosofía del manifiesto ágil, a partir de unos valores y principios que expone la siguiente figura.

\section{Sistema Nacional de Innovación}

El Sistema Nacional de Innovación (SIN), está conformado por entes del sector público y privado, cuyo trabajo mancomunado genera un crecimiento económico y bienestar social.

En Colombia se tienen centros de apoyo en innovación y tecnología, los cuales buscan dar soluciones efectivas a problemas empresariales. Estos centros son:

- Los Centros de Desarrollo Tecnológico (CDT)

- Los centros Regionales de Productividad (CRP)

- Las Incubadoras de Empresa de Base Tecnológica (IEBT)

Es importante destacar que el sector educativo en general y sobre todo el universitario producen ideas, conceptos y conocimientos que no tienen directamente un uso comercial, pero que pueden servir de insumo para que surjan las innovaciones tecnológicas, proceso generalmente realizado por las empresas.

Por tal razón es de vital importancia establecer un lazo fuerte de comunicación entre la universidad y la empresa, con el fin de generar una colaboración de mutua conveniencia, que permita satisfacer las necesidades de ambas partes, logrando así una relación siempre provechosa. Las universidades desarrollan y potencializan las capacidades intelectuales y actitudes sociales de los estudiantes, las cuales se van a ver representadas en un ambiente laboral; es allí cuando se cumple la misión de la mayoría de las universidades, cuando sus egresados prestan un servicio a la sociedad, y uno de estos servicios es la vida laboral en las empresas.

La empresa, por su parte, requiere de profesionales con conocimientos, habilidades específicas y actitudes críticas, que impulsen el crecimiento de la economía de las empresas donde laboran.

Lo anterior produce un punto de intersección, en donde, para lograr el éxito, se resalta la colaboración, proyección y responsabilidad de ambas partes (empresa y universidad). Comunicar socialmente el interés particular de los estudiantes y su contexto familiar, el de los empresarios, incluso el del país, permitirá satisfacer simultáneamente las necesidades de las universidades y empresas; cuando hay armonía entre estas dos partes se favorece el crecimiento particular y general de los intereses de la sociedad.

\section{Entidades e instrumentos de apoyo a los acuer- dos de cadenas y clúster}

Dentro de las prioridades del Ministerio de Industria, Comercio y Turismo ${ }^{5}$ para el 2012, se encuentra la de "Encaminar a Colombia por la senda de la transformación productiva, mediante el mejoramiento de los sectores ya establecidos, y el desarrollo de nuevos sectores emergentes". En este sentido, se ha planteado que el país requiere de una completa transformación industrial, que le permita tener bienes y servicios para ofrecer al mundo; lo cual se logrará mediante el desarrollo de nuevos sectores emergentes que incluyan el software y los servicios de TI.

Para lograr esta meta, el Ministerio de Industria, Comercio y Turismo se ha propuesto una táctica, que tiene como protagonista al software para el desarrollo tecnológico del mercado. En dicha táctica se proyecta que, a 2019, el software sea considerado un clúster de clase mundial, para cuyos efectos se tiene establecido avanzar en los siguientes aspectos:

- Mejoramiento de la infraestructura

- Fortalecimiento de sector

- Generar una normatividad de apoyo

- Desarrollar el factor humano del sector

5 Ver: http://www.mincomercio.gov.co/eContent/NewsDetail.asp? $\mathrm{ID}=6581 \& \mathrm{IDCompany}=1$ 


\section{Metodología}

\section{Participantes}

La investigación que lleva por título "Prácticas de desarrollo de software en las empresas pequeñas y medianas de desarrollo de software en Bogotá", se llevó a cabo, como su nombre lo indica, en la ciudad de Bogotá, durante el segundo semestre del 2010. Para esta investigación se obtuvo la información de 100 empresas, cuyo único criterio de selección era pertenecer al rubro del desarrollo de software. Luego de llevar a cabo la selección, se procedió a la aplicación de un instrumento, conformado por 20 ítems, que permitió identificar las determinadas prácticas de desarrollo del software.

\section{Instrumentos y cuestionario}

¿Por qué un cuestionario? Un cuestionario proporciona un mecanismo estructurado para la reunión de información. Ya que es posible hacer la misma pregunta a un número de encuestados. Los cuestionarios son regularmente distribuidos entre una muestra de la población objetivo y las respuestas se reúnen y resumen mediante análisis estadístico. Por otro lado, el cuestionario se debe diseñar cuidadosamente para una máxima efectividad. Así, por ejemplo, este cuestionario fue aplicado dos veces, en la primera aplicación, para estructurar el documento. Luego se determinó que las preguntas deberían reestructurarse y modificarse para una mayor comprensión, debido a esto, se llevo a cabo una segunda y final aplicación general a 100 empresas del sector en Bogotá.

La recolección de los datos se hizo mediante la aplicación de un instrumento de medición que consta de 20 ítems en total. Buscando, de esta manera, realizar un diagnóstico general de estas empresas en cuanto a las prácticas de desarrollo de software.

\section{Procedimiento}

La presente investigación tuvo cuatro momentos que se describen a continuación:

- Realización del cronograma de actividades internas del proyecto. Para lo cual se identificaron las estrategias a utilizar y se calcularon los costes directos tangibles.

- Construcción del marco teórico. En esta fase se resaltaron las principales temáticas concernientes al entendimiento del desarrollo de software.

- Diseño del instrumento de aplicación para la recolección de los datos, con base en la revisión previamente realizada. En este tercer momento se propuso realizar la aplicación del instrumento a las empresas, para lo cual se contó con la colaboración de estudiantes que trabajaban, en ese momento, en organizaciones que se encontraban en el rubro, cumpliendo así con el criterio de selección.

- En un último momento se efectuó la tabulación, graficación, descripción y análisis de los datos. A partir de allí, se realizaron la conclusión y las recomendaciones acerca de las prácticas de desarrollo de software de las empresas dedicadas a esta labor en Bogotá.

\section{Resultados y análisis de datos}

Para cumplir con los objetivos de este estudio, y siguiendo la forma en la que fue diseñado el instrumento de investigación, el análisis de datos se realizó con un enfoque cualitativo. De acuerdo con Hernández y Batista (2003), el mayor reto, a la hora de realizar un análisis cualitativo, es poder discriminar aquellos aspectos que no son relevantes para el objeto de investigación.

A continuación se exponen las preguntas del instrumento utilizado y su respectivo análisis.

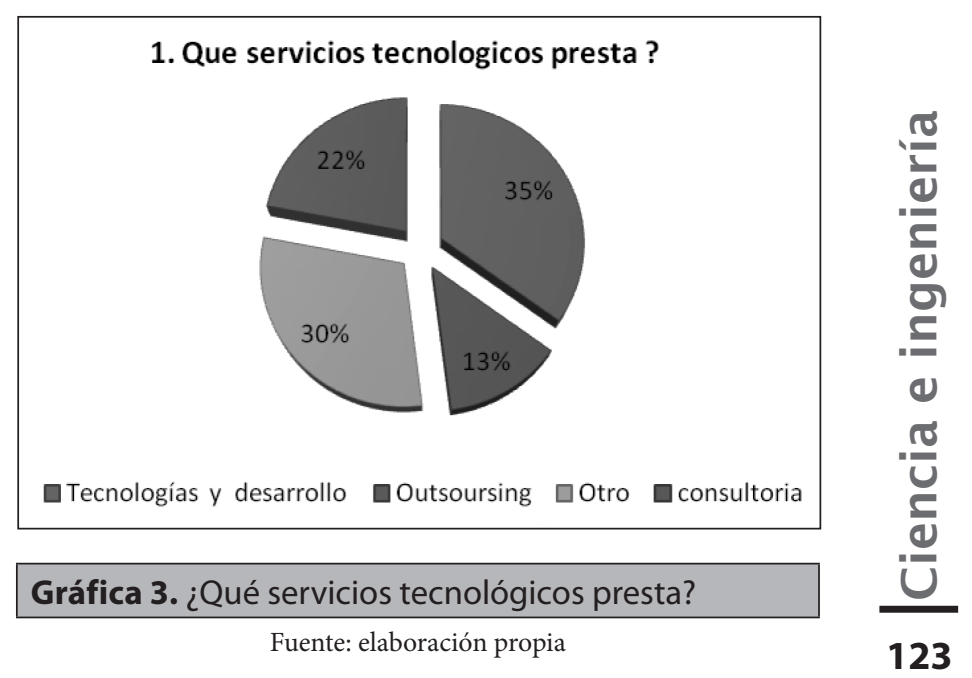


La gráfica 3, titulada “¿Qué servicios tecnológicos presta?", recoge las respuestas de 100 empresas encuestadas, de la siguiente forma: $35 \%$ contestaron que sus servicios están dentro de las tecnologías y el desarrollo, el $22 \%$ hace consultoría tecnológica, el $30 \%$ presta algún otro servicio tecnológico, y el $13 \%$ brinda outsourcing. Lo anterior, proporciona una visión clara acerca de la importancia de los servicios tecnológicos y el desarrollo de software como uno de los servicios más utilizados.

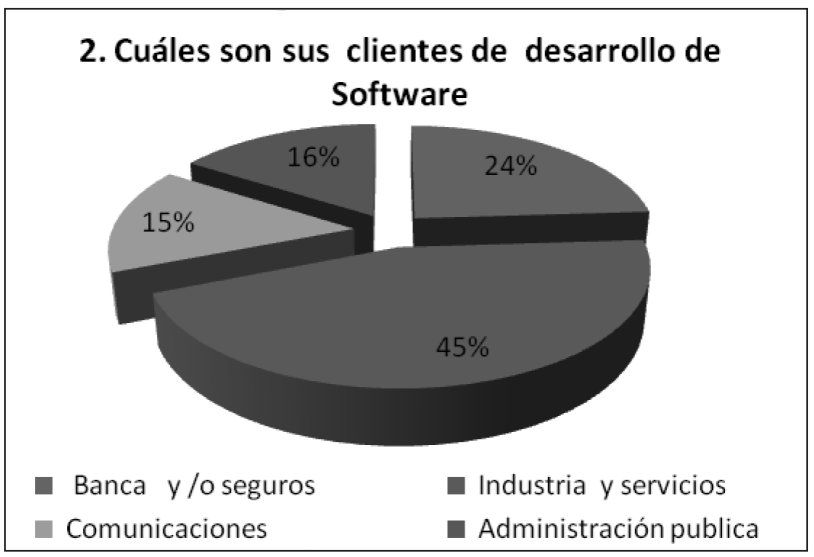

Grafica 4. ¿Cuáles son sus clientes de desarrollo de software?

Fuente: eleboración propia

Frente a la pregunta “¿Cuáles son sus clientes de desarrollo de Software?” (Gráfica 4), las empresas encuestadas respondieron de la siguiente forma: el $45 \%$ manifiesta que sus clientes están dentro del sector de la industria y los servicios, el $24 \%$ dice que sus clientes están dentro de la banca y los seguros, el 15\% están con telecomunicaciones y el 16\% dentro de la administración pública. A partir de lo anterior, se puede inferir que el nicho de mercado de los productos de software se encuentra en la industria y los servicios, como se puede determinar a través de las respuestas obtenidas por las empresas encuestadas.

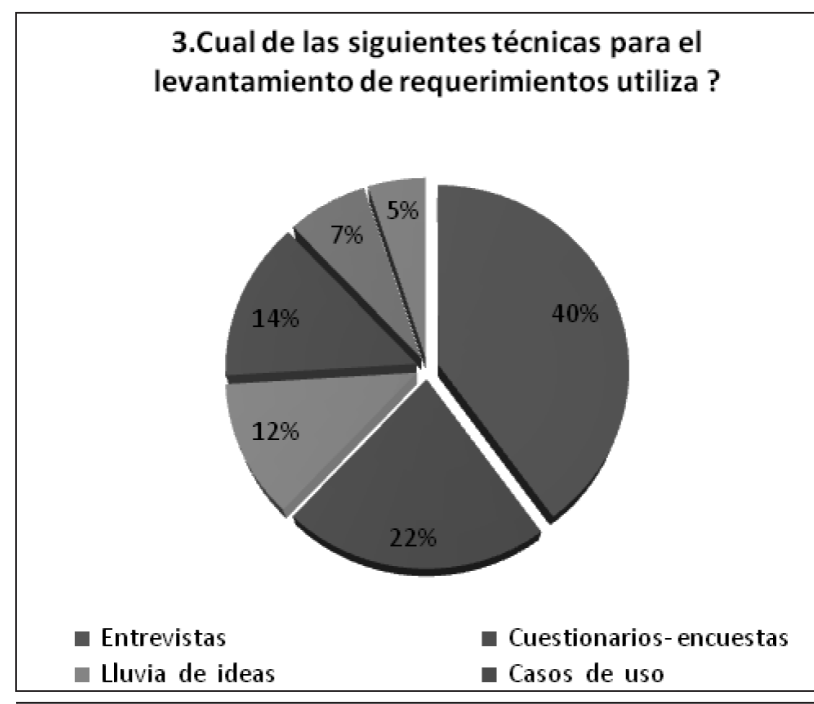

Gráfica 5. ¿Cuál de las siguientes técnicas emplea para el levantamiento de requerimientos?

Fuente: elaboración propia

En la gráfica 5, frente al ítem “¿Cuál de las siguientes técnicas emplea para el levantamiento de requerimientos?", en la aplicación del instrumento se determina que el $40 \%$ aplican las entrevistas, el $22 \%$ los cuestionarios y encuestas, el $14 \%$ los casos de uso, el $7 \%$ realiza prototipos, el $5 \%$ organiza reuniones JAD y solo el $12 \%$ práctica la lluvia de ideas. Como se puede observar, la combinación de entrevistas, casos de uso, aplicación de cuestionarios y encuestas, junto con los prototipos, conforman las prácticas más utilizadas por las empresas para extraer los requerimientos del usuario.

4. Que modelos de proceso de desarrollo utiliza?

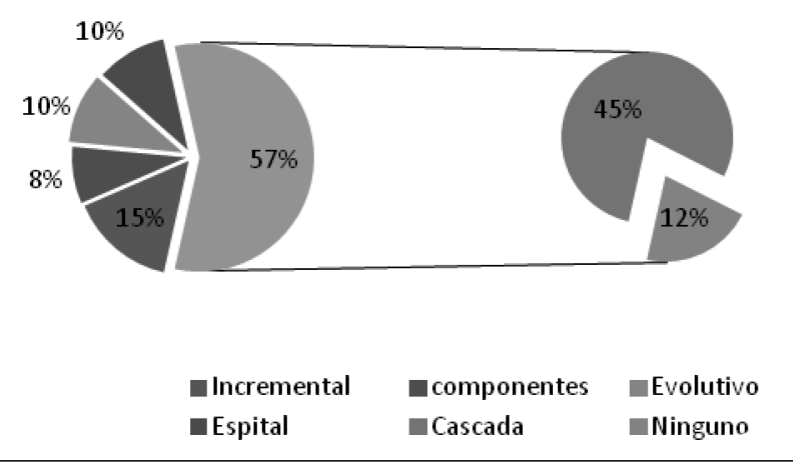

Gráfica 6. ¿Qué modelos de proceso de desarrollo utiliza?

Fuente: elaboración propia 
La gráfica 6, recoge las respuestas de las empresas frente a la pregunta "¿Qué modelos de proceso de desarrollo utiliza?", de la siguiente forma: $45 \%$ modelo cascada, $15 \%$ modelo incremental, el 12\% no utilizan ningún modelo de desarrollo, el $10 \%$ modelo evolutivo, el $10 \%$ espiral y el $8 \%$ trabaja con el modelo por componentes.

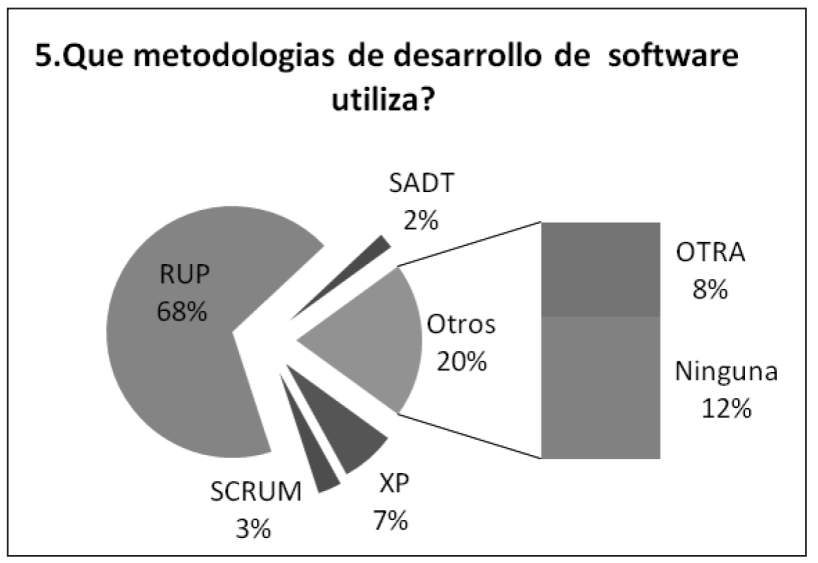

Gráfica 7. ¿Qué metodologías de desarrollo de software utiliza?

Fuente: elaboración propia

Frente al ítem "¿Que metodologías de desarrollo de software utiliza?” (Gráfica 5), las empresas encuestadas dieron como resultado los siguientes porcentajes: $68 \%$ la metodología RUP, el $20 \%$ utiliza otras metodologías en las cuales están inmersas otras con el $8 \%$, el $12 \%$ no emplea ninguna, el $7 \%$ la metodología XP, el 3\% la SCRUM y el 2\% la SADT.

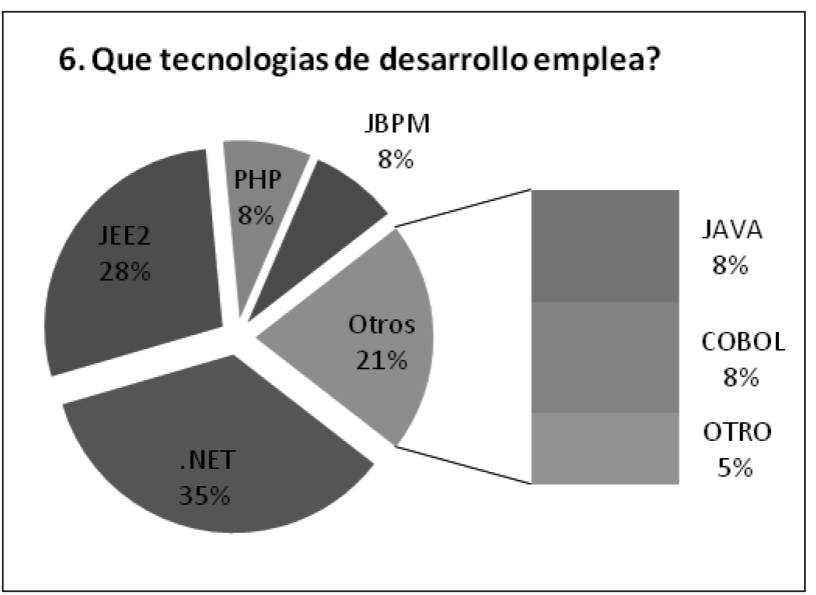

Gráfica 8. ¿Qué tecnologías de desarrollo emplea?

Fuente: elaboración propia
La grafica 8 contiene las respuestas a la pregunta “QQué tecnologías de desarrollo emplea?”. El 35\% emplea plataforma NET; el $28 \%$ JEE2; el $21 \%$ emplea otras que contienen Java y Cobol con el $8 \%$, respectivamente; otros con el 5\%; PHP con el 8\% y el JBPM con el $8 \%$.

7. Cuál es la duración promedio de los proyectos de desarrollo?

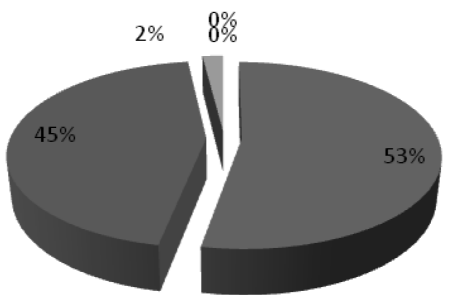

1 a 4 mese 5 a 10 mese 10 a 15 meses Mas 16 mese Otro cual

Gráfica 9. ¿Cuál es la duración promedio de los proyectos de desarrollo?

Fuente: elaboración propia

Con respecto al ítem “¿Cuál es la duración promedio de los proyectos de desarrollo?” (Gráfica 9), se observa un gran porcentaje en proyectos de corta duración (53\% de 1 a 4 meses), un $45 \%$ con proyectos entre 5 y 10 meses y un pequeño porcentaje del $2 \%$ con entregas de otra duración.

\section{Cuál es la proporción de proyectos de desarrollo cancelados por año?}

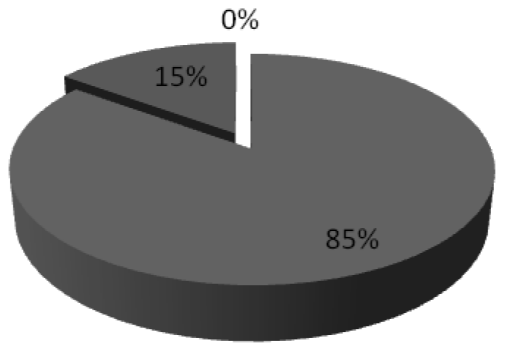

a. 0 a 35

b. 36 a 65

c. 66 a 100

Gráfica 10. ¿Cuál es la proporción de proyectos de desarrollo cancelados por año?

Fuente: elaboración propia 
En la gráfica 8, “¿Cuál es la proporción de proyectos de desarrollo cancelados por año?", las empresas encuestadas respondieron, en un alto porcentaje, que los proyectos cancelados fueron del $85 \%$, durante el año, y solo el 15\% no fueron cancelados.

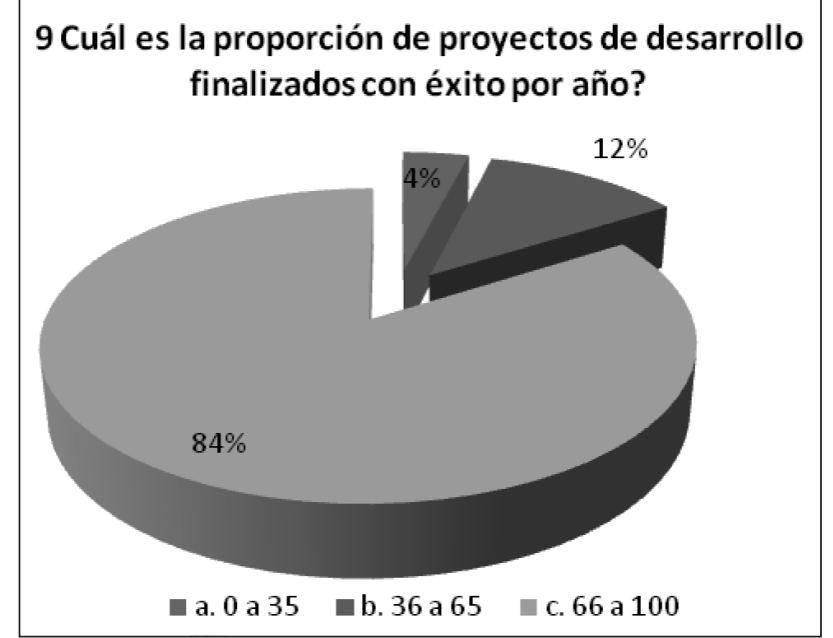

Gráfica 11. ¿Cuál es la proporción de proyectos de desarrollo finalizados con éxito por año?

Fuente: elaboración propia

Frente a esta pregunta, las empresas encuestadas señalaron que un $84 \%$ entrega entre 66 y 100 proyectos por año, el $12 \%$ de 36 a 65 proyectos y el $4 \%$ de 0 a 35 proyectos por año.

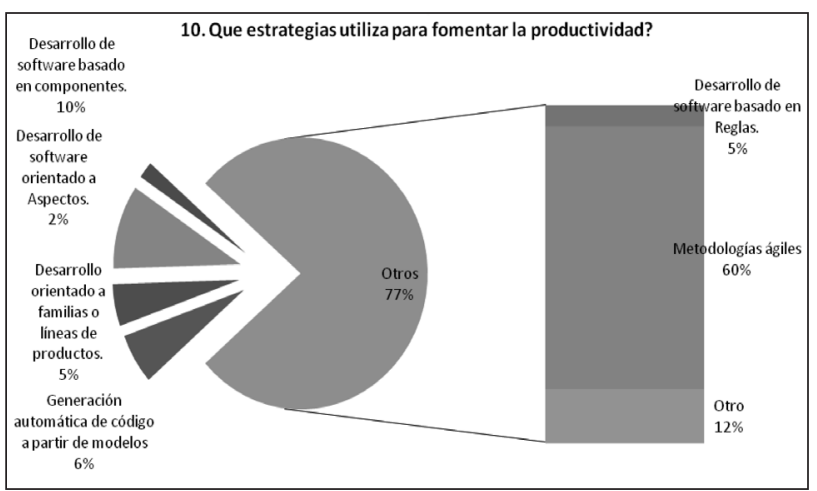

Gráfica 12. ¿Qué estrategias utiliza para fomentar la productividad?

Fuente: elaboración propia
En la gráfica 10, frente al ítem “¿Qué estrategias utiliza para fomentar la productividad?", se observa que un alto porcentaje (60\%) implementa estrategias de metodologías ágiles, un 10\% metodologías basadas en componentes, el $12 \%$ otras metodologías, el 6\% generación automática de código a partir de modelos, el 5\% desarrollo orientado hacia las

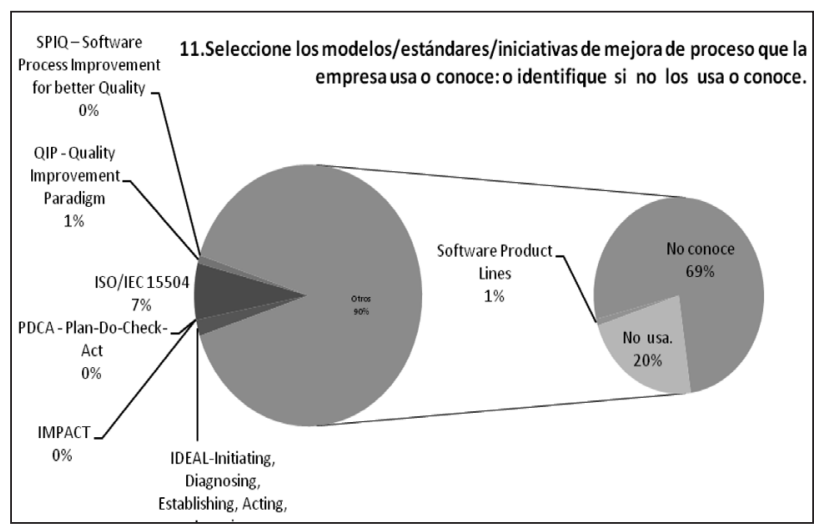

familias o líneas de productos, y el último 5\% está representado por el desarrollo de software basado en reglas.

\section{Gráfica 13. Seleccione los modelos/estándares/} iniciativas de mejora de proceso que la empresa usa o conoce; o identifique si no las usa o conoce

Fuente: elaboración propia

La gráfica 13, referente a la pregunta "Seleccione los modelos/estándares/iniciativas de mejora de proceso que la empresa usa o conoce; o identifique si no los usa o conoce", muestra que el $69 \%$ no los conoce, el 20 no los utiliza, el $2 \%$ trabaja con el modelo ideal, el 1\% maneja QIP y otro $1 \%$ emplea el Software Product Lines.

Lo que se detecta es la falta de conocimiento y utilización de los estándares que se utilzan en el desarrollo de software. Es necesario e importane conocerlos para generar productos de software confiables, robustos y que cumplan los requisitos exigidos por los usuarios. 


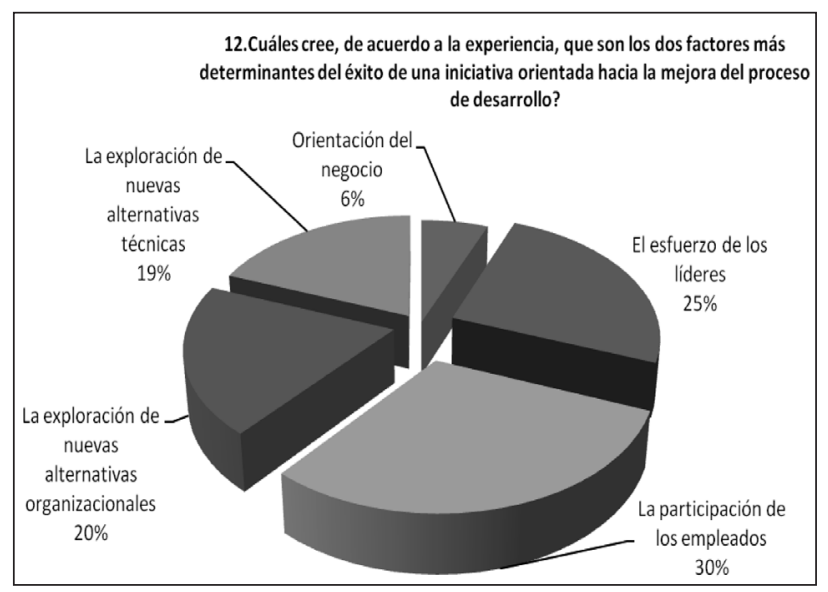

Gráfica 14. ¿Cuáles cree, de acuerdo con su experiencia, que son los factores más determinantes del éxito de una iniciativa orientada hacia la mejora del proceso de desarrollo?

Fuente: elaboración propia

Frente al ítem “¿Cuáles cree, de acuerdo con su experiencia, que son los factores más determinantes del éxito de una iniciativa orientada hacia la mejora del proceso de desarrollo?", las empresas respondieron de la siguiente forma: $30 \%$ la participación de los empleados, $25 \%$ los esfuerzos del líder, $20 \%$ la exploración de las nuevas alternativas de organización, 19\% la exploración de nuevas altenativas técnicas, y un $6 \%$ la orientación del negocio.

El factor humano en los procesos actuales es de vital impotancia, ya que son los trabajadores quienes conocen y manejan los procesos implícitos y los proyectan de maneta explícita hacia los productos de desarrollo. Así mismo, generar una interacción con los líderes hace parte de un clima organizacional que genera resultados.

\section{3 ¿Hay un sistema de gerencia de la calidad?}
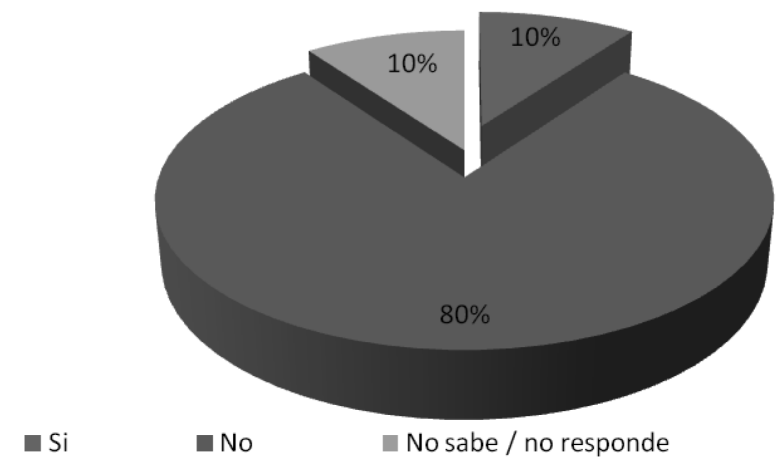

Gráfica 15. ¿Hay un sistema de gerencia de la calidad?

Fuente: elaboración propia

En la gráfica 15, frente al ítem “¿Hay un sistema de gerencia de la calidad?", las empresas encuestadas respondieron lo siguiente: el $80 \%$ no tiene un sistema de calidad en la gerencia, un $10 \%$ sí lo tiene y un $10 \%$ no sabe o no responde. De donde podemos inferir que las empresas analizadas no tiene un plan de calidad establecido.

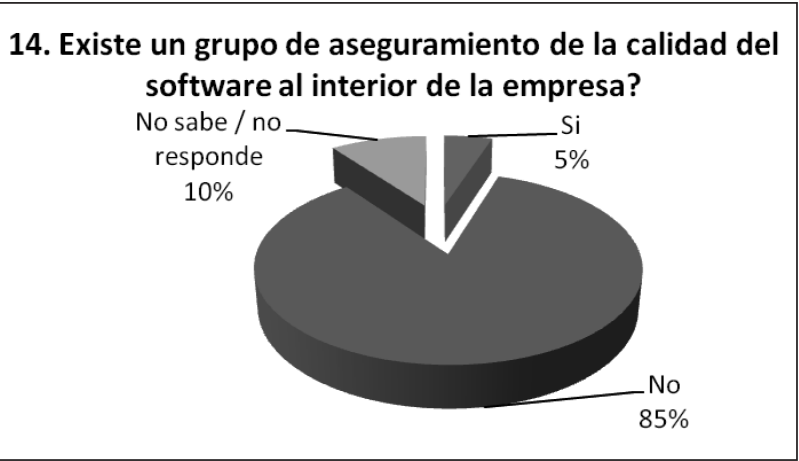

Gráfica 16. ¿Existe un grupo de aseguramiento de la calidad del software al interior de la empresa?

Fuente: elaboración propia

Frente a la pregunta, “¿Existe un grupo de aseguramiento de la calidad del software al interior de la empresa?, el $85 \%$ respondió que no, el $10 \%$ no sabe o no responde y el $5 \%$ sí presenta un grupo de aseguramiento de la calidad del software al interior de la empresa. 


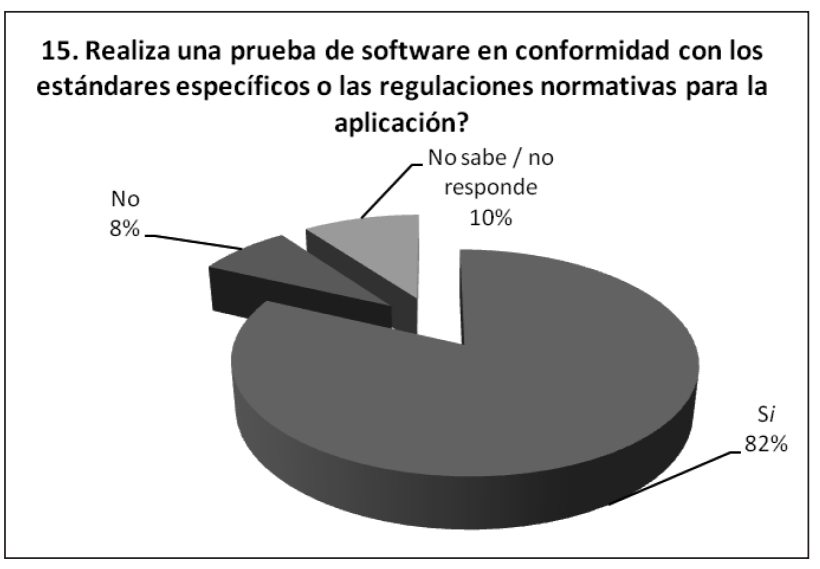

Gráfica 17. ¿Realiza una prueba de software conforme a los estándares específicos o las regulaciones normativas para la aplicación?

Fuente: elaboración propia

Frente a la pregunta “ ¿Realiza una prueba de software conforme a los estándares específicos o las regulaciones normativas para la aplicación?", el $82 \%$ de las empresas encuestadas respondió que realiza las pruebas de software, el $10 \%$ no sabe o no responde y el $8 \%$ no realiza pruebas.

16. Existe un manual/documento de gerencia de la calidad?

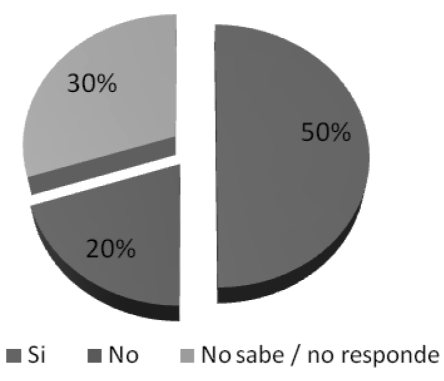

Gráfica 18. ¿Existe un manual o documento de gerencia de la calidad?

Fuente: elaboración propia

Frente a la pregunta “¿Existe un manual o documento de gerencia de la calidad?", la aplicación del instrumento arrojó que el 50\% sí tiene un manual de calidad, el $30 \%$ no sabe o no conoce y el $20 \%$ no lo tiene.

En virtud de lo anterior, se puede determinar que las empresas sí tienen un documento que orienta hacia la consecución de la calidad pero sus funcionarios no lo conocen. Por lo tanto, es vital hacer la inducción a empleados nuevos, la cual debe ir acompañada de jornadas de información al respecto para el resto del personal.

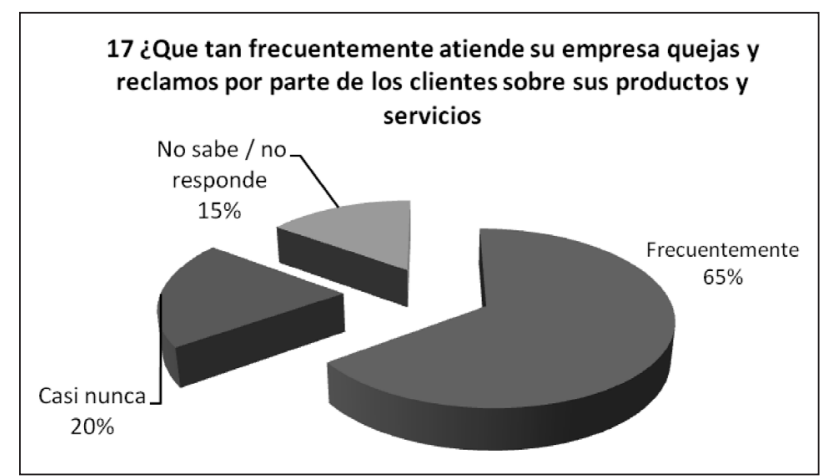

Gráfica 19. ¿Qué tan frecuentemente atiende su empresa quejas y reclamos, por parte de los clientes, sobre sus productos y servicios?

Fuente: elaboración propia

En la gráfica 19, frente al ítem “¿Qué tan frecuentemente atiende su empresa quejas y reclamos, por parte de los clientes, sobre sus productos y servicios?", el porcentaje obtenido es del $65 \%$ frecuentemente, el $20 \%$ casi nunca y el $15 \%$ no sabe o no responde.

\section{Conclusiones}

En el transcurso de la tabulación, graficación, descripción y análisis de los datos obtenidos, mediante el instrumento de medición, se pudo identificar qué prácticas de desarrollo del software realizan las empresas de Bogotá. Sobre las cuales habría que considerar, sin embargo, varios aspectos:

- El micho de mercado de productos de software está dentro de la industria y los servicios, como se determina a partir de las respuestas obtenidas por las empresas encuestadas.

- En cuanto a las prácticas de desarrollo de software existe una combinación entre entrevistas, casos de uso, la aplicación de cuestionarios y encuestas, junto con los prototipos.

- El modelo más utilizado por las empresas encuestadas es el de cascada mejorado. Este 
modelo es uno de los más antiguos y es combinado con la metodología RUP, lo que genera un híbrido interesante de estudiar. Lo anterior debido a que la metodología RUP está sustentada por las disciplinas de desarrollo de software y además involucra el moldeamiento UML.

- Los proyectos de software están dentro del rango de proyectos cortos con un 53\% y con entregas exitosas, aunque se ha podido determinar una generalizada demora en la entrega final.

- Se detectó que hace falta conocimiento en la utilización de los estándares de calidad de desarrollo de software, tanto por parte de las empresas como de las personas. Así mismo, las empresas que cuentan con algún plan estándar no lo dan a conocer a los empleados.

- Otro aspecto relevante es el factor humano. En los procesos actuales se detectó que este es de vital impotancia, ya que los trabajadores son quienes conocen y manejan los procesos implícitos y los proyectan de maneta explícita hacia los productos de desarrollo.

Lo anterior confirma la necesidad latente no solo de armonizar el sistema social y económico con la demanda de oferta, sino con la calidad de la oferta que se produzca en la ciudad de Bogotá, la cual puede llegar, mediante el engranaje perfecto de la teoría y las herramientas tecnológicas, a convertirse en el epicentro de este contexto y constituir, por qué no, una salida a las múltiples problemáticas que sufre nuestro sector en cuanto al desempleo actual.

\section{Recomendaciones}

- Si bien la academia es un espacio donde se construye el ser crítico en los estudiantes y se les forma en principios activos, para su posterior engranaje en el sistema actual, la radiografía de nuestra sociedad colombiana no da cuenta de ese difícil propósito. Y, sin entrar a determinar, formular hipótesis o discutir acerca de los muchos aspectos de la educación, podríamos partir de un supuesto básico y esencial: adentrarnos en una de las muchos partes del problema, tal y como lo hizo la introducción, justificación y marco teórico de la presente investigación.

- Existe una creciente demanda de productos de software de alta calidad y, por ende, las prácticas del desarrollo del software son el vehículo para que esto sea posible y se logre la competitividad y productividad necesarias para suplir con éxito el mercado nacional e internacional.

- A partir de la presente investigación se puede formular una línea temática que, en una primera instancia, aborde temas como las cadenas productivas en general, cómo el desarrollo de productos de software incide en su potencialización y, por ende, cómo el clúster de software debe fortalecer sus lineamientos para llegar a desarrollarse.

- En cuanto a las prácticas de desarrollo de software, debe generarse un espacio a nivel de educación superior y empresarial para determinar las necesidades reales de la región y así contextualizar el sector. Es importante que las empresas se preocupen no solo por terminar un producto de software sino que lleven el control de calidad de dicho producto para ser así más competentes dentro de los mercados.

- Las empresas del sector estudiado en esta investigación, no llevan una metodología, la mayoría no lleva un modelo de desarrollo, no conoce los estándares de calidad, no lleva una documentación adecuada de sus productos y la planeación de las actividades presenta muchas falencias. De allí que el $84 \%$ de las entregas anuales presente demoras

- Sin embargo, los productos terminados son de buena calidad, eficientes y presentan competitividad, la cual puede llegar a ser una gran escala si se manejan efectivamente las buenas prácticas de desarrollo de software establecidas por los diferentes estándares.

- Es necesario construir un instrumento de medición específico, en cuanto a modelos de desarrollo de software, estándares de calidad en el proceso de desarrollo de software, metodologías de desarrollo de software, 
levantamiento de requerimientos de desarrollo de software, entre otros temas.

- Conformar sólidamente este grupo para dar orientación operativa y teórica a las pymes. También es necesario realizar un fortalecimiento frente a las falencias, encontradas en la operatividad del sector laboral. De manera general, es necesario resaltar la constante realimentación que hubo por parte de los estudiantes que trabajan en empresas relacionadas, acerca de los diferentes parámetros del desarrollo de software. Lo cual brindo a la investigación un soporte referente a la necesidad de conformar este observatorio, como punto de partida de nuevas investigaciones, adelantos y orientaciones empresariales o académicas.

- Derivar investigaciones a través de los hallazgos del observatorio de las prácticas de desarrollo de software de pequeñas y medianas empresas de desarrollo de software en Bogotá.

\section{Bibliografía}

Castaño, C. E.; Granda, M. Y.; Lopera, E. N. y Rodríguez, A. F. (2007). "Hacia un nuevo Planteamiento de la contaduría pública frente a la realidad de las micro, pequeñas y medianas empresas (MIPYMES)". En III Congreso de Estudiantes de Contaduría Pública. Pontificia Universidad Javeriana, Bogotá, pp. 1-15.

Correa, J. A. (2006). "Algunas reflexiones en torno a la interacción de los contadores públicos en las pequeñas empresas". En Contaduría Universidad de Antioquia, núm. 49, pp. 73-86. Medellín.

Malassis, (1992) revista Agroalimentaria, vol. 14, núm. 26, enero-junio, 2008, pp. 13-16 Universidad de los Andes, Mérida, Venezuela.

Pressman, R. S. (2003). Ingeniería del Software, un enfoque Práctico (Quinta edición edición). Mc Graw Hill.

Documento CONPES 3484. (2007). Política nacional para la transformación productiva y la promoción del micro, pequeñas y medianas empresas: un esfuerzo público-privado.

Ley 78 de 1988. Fomento para la microempresa y la pequeña y mediana industria.

Ley 590 de 2000. Promoción del desarrollo de las micro, pequeñas y medianas empresas.

Ley 905 de 2004. Modifica la Ley 590 de 2000 sobre promoción del desarrollo de las micro, pequeña y mediana empresa colombiana.

Ley 1014 de 2006. Fomento a la cultura del emprendimiento.

Ley 1151 de 2007. Plan Nacional de Desarrollo $2006-2010$.

Meigs, R.; Williams, J.; Haka, S. y Bettner, M. (2000). Contabilidad: la base para la toma de decisions gerenciales, (11 edición). Bogotá: Mc Graw Hill.

Ramírez, J. C. (2007). "La consultoría: un acelerador del crecimiento en las PYMES”. En Revista Latinpyme, núm. 29, año 6, pp. 13-16.

Sinisterra, G.; Polanco, L. E. y Henao, H. (2005). Contabilidad: sistema de información para las Organizaciones, ( $5^{\circ}$ edición). Bogotá: Mc Graw Hill.

Zeballos, E. (2000). Restricciones del entorno a la competitividad empresarial en América

Latina. San José: Fundes International. 